\title{
Tumors with Pilosebaceous Differentiation: A Five Year Retrospective Study at BPKIHS
}

\author{
Paudyal $\mathbf{P}^{1^{*}}$, Pradhan $\mathbf{A}^{1}$, Pokharel $\mathbf{S}^{1}$, Sah $\mathbf{N}^{1}$, Karki $\mathbf{S}^{1}$, Marhatta $\mathbf{S}^{\mathbf{2}}$ \\ ${ }^{1}$ Department of Pathology, ${ }^{2}$ Department of Dermatology \& Venereology \\ B. P. Koirala Institute of Health Sciences, Dharan, Nepal
}

\author{
Keywords \\ Keratoacanthoma, Pilomatrixoma, \\ Pilosebaceous differentiation.

Corresponding author
*Dr Punam Paudyal
Associate Professor
Department of Pathology
B P Koirala Institute of health sciences,
Dharan, Nepal
Email: punam.paudyal@bpkihs.edu

\begin{abstract}
Background: Skin appendageal tumors (SAT) are a large and diverse group of tumors that are commonly classified according to their state of appendageal differentiation: Follicular, sebaceous, eccrine and apocrine. Most adnexal neoplasms are uncommonly encountered in routine practice, and pathologists can easily recognise frequently encountered tumours. In this study, the histological features of important benign and malignant tumors of pilosebaceous origin were reviewed considering its morphologic types, subtypes, age, sex and anatomic site.
\end{abstract}

Methods: This is a hospital based retrospective study which includes all cases of tumors with pilosebaceous differentiation diagnosed histologically during the period of five years ( $1^{\text {st }}$ January, 2008 to $31^{\text {st }}$ December, 2012). Tumors were analyzed considering the anatomic location and type of the tumor, along with age and sex of the patient. The Histological characterization was done according to the WHO classification system for SAT. Collected data were entered in Microsoft Excel 2000 and converted it into SPSS PC+ 11.5 Version for statistical analysis.

Results: A total of 53 neoplasms of pilosebaceous differentiation included, 52 (98.1\%) were benign and one (1.8\%) was malignant. The mean age was 39.23 years. Females comprised of $35(66 \%)$ and 18 (34\%) were males. Most common location was in head and neck area. Of all, 51 (96.2\%) tumors were follicular, and two (3.7\%) were with sebaceous differentiation. Among all follicular tumors, Pilomatricoma (33.9\%), Keratoacanthoma (26.4\%) and Trichoepithelioma (22.6\%) were the commonest tumors observed.

Conclusion: The study findings reveal majority of the tumors origin were of follicular differentiation and all were benign.

\section{INTRODUCTION}

Skin appendageal tumors (SAT) are those neoplasms that differentiate toward or arise from pilosebaceous apparatus, apocrine, and eccrine glands. Clinical diagnosis of different entity is often difficult, as most of them present as asymptomatic papules or nodules ${ }^{1}$. Anatomic location, number and distribution of lesions provide important clue but histopathology is invaluable in confirmation of the diagnosis ${ }^{2}$. These tumors basically originate from undifferentiated pluripotent stem cells and finally differentiate to specific tumors influenced by genetics, local vascularity, and the microenvironment of the epidermis and dermis ${ }^{3,4,5}$. They are usually missed clinically and often confirmed by histopathology ${ }^{6}$.

Most SAT are benign, and local complete surgical excision 
is curative. However, diagnosing some of these tumors has important implications, as they might be markers for syndromes associated with internal malignancies, such as trichelemmomas in cowden disease and sebaceous tumors in Muir-Torre syndrome ${ }^{7,8}$. A malignant counterpart of almost every SAT has been described. These tumours are rare, locally aggressive, and have the potential for nodal involvement and distant metastasis, with a poor clinical outcome ${ }^{9}$. Therefore establishing a diagnosis of malignancy in SAT is important for therapeutic and prognostic purposes. Because pathologists may not frequently encounter SAT, and owing to their different derivation and broad histogenesis, diagnosing these tumors may be challenging even to an experienced pathologists ${ }^{9}$.

\section{OBJECTIVES}

The main objectives of this study were to study the histopathologic spectrum of tumors with pilosebaceous differentiation and its clinicoepidemiological profile.

\section{METHODS}

This is a hospital based retrospective study spanning over a period of five years conducted in the section of histopathology department of B P Koirala institute of Health Sciences (BPKIHS), Dharan, nepal.

All the diagnosed cases of pilosebaceous tumors over a period of five years from $1^{\text {st }}$ January, 2008 to $30^{\text {th }}$ December, 2012 were retrieved from the indexed histopathology files of the Pathology Department, BPKIHS. The clinical data of the patients were obtained from their respective files.

All skin biopsies sent from the Department of Dermatology and Venerology were fixed in $10 \%$ formalin, processed in paraffin wax and stained with Haematoxylin and Eosin and were subjected for histopathological examination.

Out of total 70 skin adnexal tumors (SAT) diagnosed histologically during this study period, only 53 SATs revealing pilosebaceous differentiation were included in the study. The Histologic characterization according to the WHO classification system for skin tumors was done. Tumors were categorized with respect to age, sex and anatomic site as well. Cases clinically diagnosed as
SAT but not histologically and tumors with eccrine and apocrine differentiation were excluded from the study.

Collected data were entered in Microsoft Excel 2000 and converted it into SPSS $\mathrm{PC}^{+} 11.5$ version for statistical analysis. The descriptive statistics were presented in percentage, proportion, tabular forms and mean and standard deviation were calculated. For inferential statistics odds ratio, chi square test with p-values were calculated at the level of significant at 95\%, to find out the relationship between dependent variables and independent variables.

Approval was taken from the Institutional Review Committee of BPKIHS before the start of the study, along with permission from the Hospital Director to obtain health records and confidentiality was maintained throughout.

\section{RESULTS}

All the patients included in this study attended BPKIHS with skin lesion. Lesions were examined clinically and were excised for clinico-histopathological correlation.

According to the WHO histological classification, they were broadly classified into four types i.e. follicular, sebaceous, eccrine and apocrine. Out of 70 cases of SATs diagnosed histologically, only 53 cases of pilosebaceous tumors have been included in the study. Most commonly diagnosed tumor was with follicular differentiation which constituted of 51 (96.22\%) cases and only 2 (3.77\%) cases were of sebaceous differentiation.

\section{Tumors with Pilar differentiation}

All the follicular tumors were benign. Among this category the commonest tumor encountered histologically was pilomatrixoma (PM), which constituted of 18 cases (33.96\%) of total (Table 1). Histology revealed a well circumscribed nodular lesion in the dermis, surrounded by fibrous stroma along with basaloid cells lining and contiguously transforming into pale eosinophilic anucleated shadow/ghost cells (Fig 1). Some showed multinucleated giant cells and calcification.

Most of these tumors were seen in fourth decade of life, comprising of $6 / 18$ cases. Majority $(13 / 18)$ of cases were observed in females and was found to be located in scalp (5/18). None of the cases of PM was diagnosed clinically as PM. Most of them were submitted as sebaceous cysts. 
Table 1: Origin, nature, histologic type of pilosebaceous tumors and its frequency

\begin{tabular}{lccc}
\hline $\begin{array}{c}\text { Origin of tumor } \\
\text { (\%) }\end{array}$ & $\begin{array}{c}\text { Nature } \\
\text { (\%) }\end{array}$ & $\begin{array}{c}\text { Histologic } \\
\text { type }\end{array}$ & $\begin{array}{c}\text { Histologic } \\
\text { diagnosis, } \\
\text { frequency } \\
\text { (\%) }\end{array}$ \\
\hline $\begin{array}{lccc}\text { Follicular tumors } \\
(96.2 \%)\end{array}$ & $\begin{array}{c}\text { Benign } \\
(96.2 \%)\end{array}$ & PM & $18(33.9 \%)$ \\
& & KA & $14(26.4 \%)$ \\
& & TE & $12(22.6 \%)$ \\
& & TF & $1(1.8 \%)$ \\
Sebaceous & Benign & Seb ad & $1(1.8 \%)$ \\
Tumors (3.7\%) & $(1.8)$ & & $1(1.8 \%)$ \\
& Malignant & Seb Ca & $1(1.8 \%)$ \\
TOTAL & $(1.8 \%)$ & & $\mathbf{5 3 ( 1 0 0 \% )}$ \\
\hline
\end{tabular}

Fig 1: Basaloid cells which are transforming into pale eosinophilic anucleated ghost cells in Pilomatricoma $(\mathrm{H}$ \& $\mathrm{E} \times 40)$

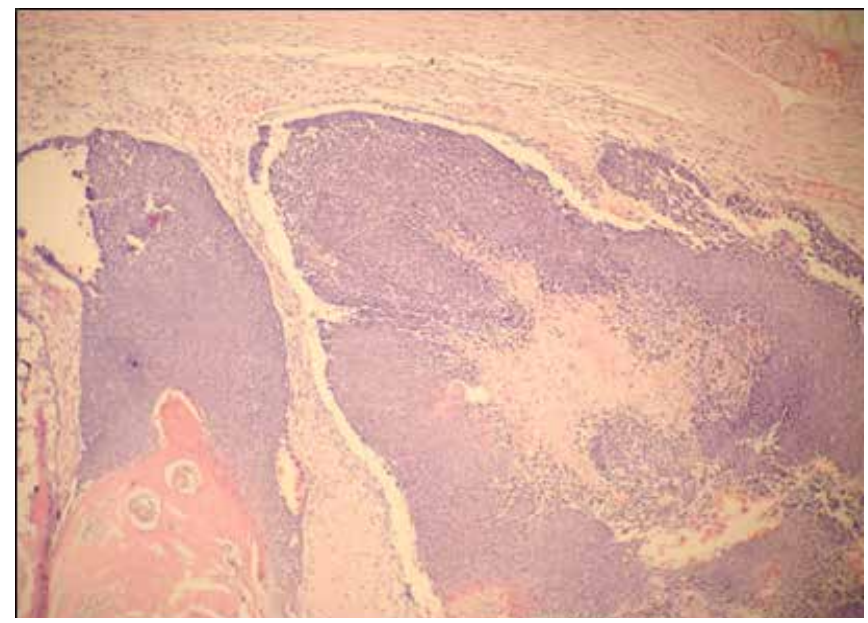

Second most common tumor with follicular differentiation was keratoacanthoma (KA), which constituted of 14/53 (26.4\%) cases. Histology revealed a central, keratin filled crater. The extension of the epidermis was seen like a lip or a buttress over the sides of the crater. At the base of the crater, irregular epidermal proliferations extend both upward into the crater and downward from the base of the crater. Many horn pearls were observed and the base appeared regular and well demarcated and does not extend below the level of the sweat glands (Fig 2). Most of these tumors were seen in fifth decade of life. There was female predominance and scalp was the commonest location. None of the cases of KA was diagnosed clinically as KA. Most of them were submitted as basal cell carcinoma.
Fig 2: Central, keratin filled crater and extension of the epidermis like a lip or a buttress over the side of the crater in keratoacanthoma (H \& E x 4)

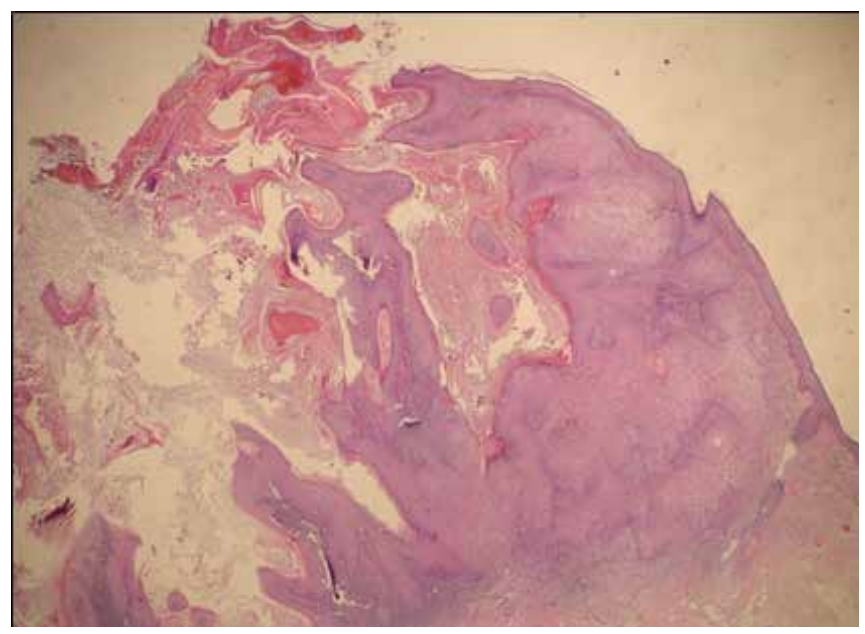

Fig 3: Lobules of uniform basaloid cells with peripheral palisading and surrounded by a fibromyxoid stroma in trichoepithelioma (H \& E x20)

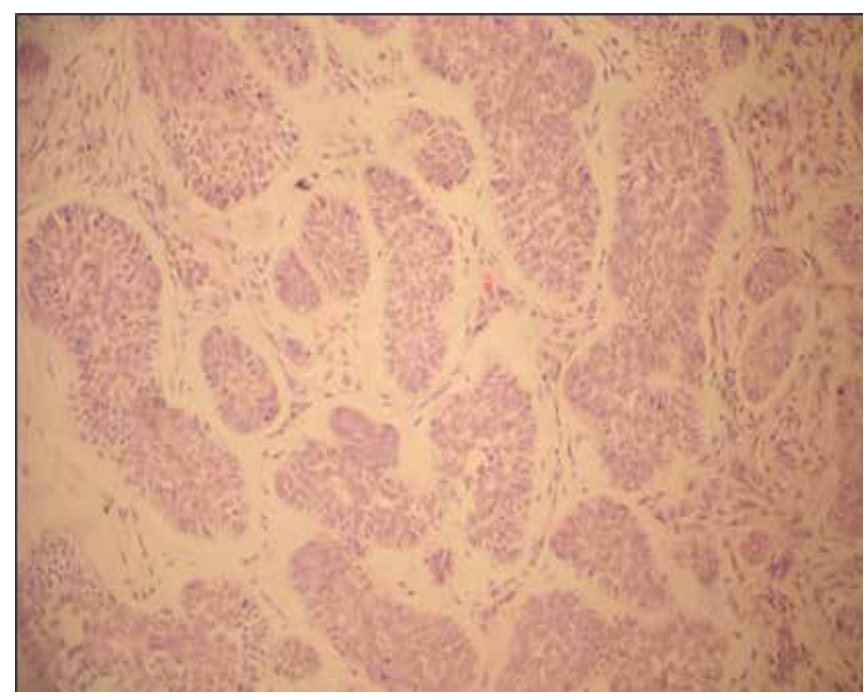

Third common tumor was trichoepithelioma (TE) which constituted of 12 (22.6\%) cases. Histology of TE reveal aggregates and branching strands of uniform basaloid cells with peripheral palisading of the nuclei arranged within a prominent fibrous stroma in the reticular dermis (Fig 3). One focus exhibits a papillary mesenchymal body with hair bulb formation. Stromal clefts and cysts lined by squamous epithelium with infundibular keratinization are present. The tumor shows no connection to an unremarkable epidermis. Most of these tumors (5/12) were seen in third decade of life. There was male (7/12) predominance and nose $(7 / 12)$ was the commonest location. Only $2 / 12$ cases of TE was diagnosed clinically as TE rest were diagnosed as basal cell carcinoma, nevus and papilloma. 
Fig 4: A symmetrical epithelial nodular proliferation and mild papillomatosis with overlying hyperkeratosis and downward growth of epithelial cells (H \& E x 20)

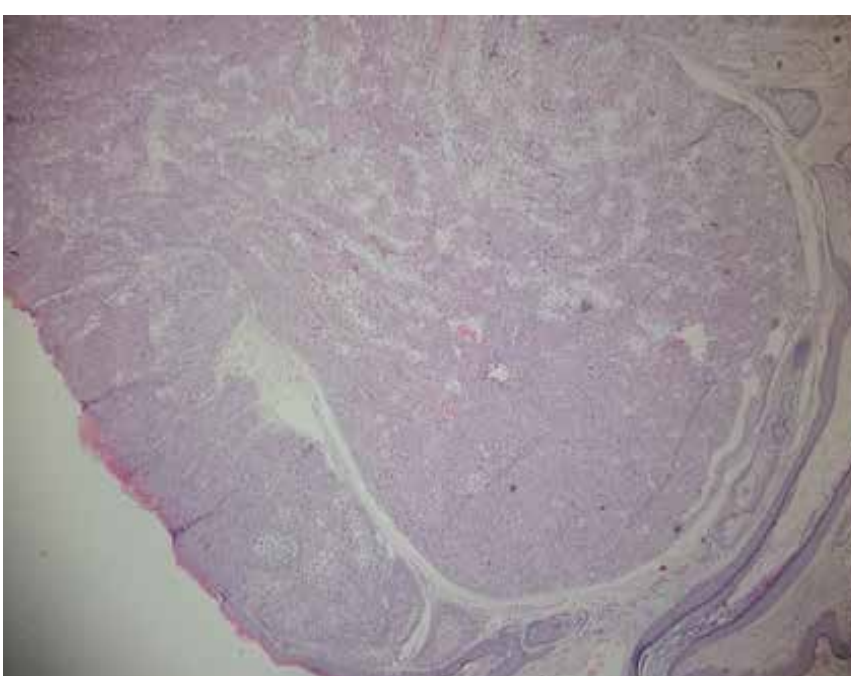

Fourth common tumor was found to be a trichilemmoma (TL) which constitutes 5 (9.4\%) cases. Trichilemmoma reveal a symmetrical epithelial nodular proliferation (Fig 4). There is mild papillomatosis with overlying hyperkeratosis and down growth of epithelial cells with increasing clear cell differentiation at the base of the lesion (Fig 5). These tumors were most commonly seen in second decade of life with male predominance and back and leg being the predominant sites.

Rest of the tumor diagnosed within follicular differentiation which did not contribute to a significant proportion of cases were trichofolliculoma (1.8\%), and trichoblastoma (1.8\%).

Fig 5: Tumor cells reveal increasing clear cell differentiation at the base of the lesion (H \& E x 40)

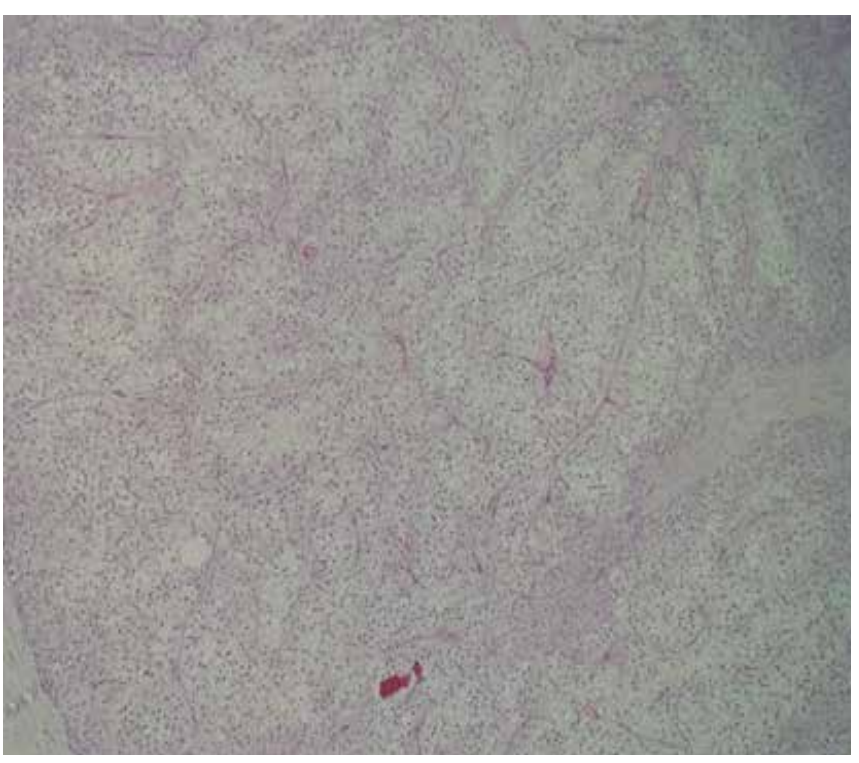

\section{Tumors with sebaceous differentiation}

Tumor with sebaceous differentiation constituted only two(3.7\%) cases (Table 1). Out of two, one $(1.8 \%)$ was benign i.e. sebaceous adenoma and thigh being the site. This was diagnosed clinically as sebaceous cyst. Another one $(1.8 \%)$ was malignant i.e. sebaceous carcinoma (Fig 6), eye lid being the site and clinically diagnosed as meibomian carcinoma. Both of these tumors were found to be occurring in females.

Fig 6: Vacuolated tumor cells arranged in lobule with central comedonecrosis in sebaceous carcinoma (H \& Ex 40)

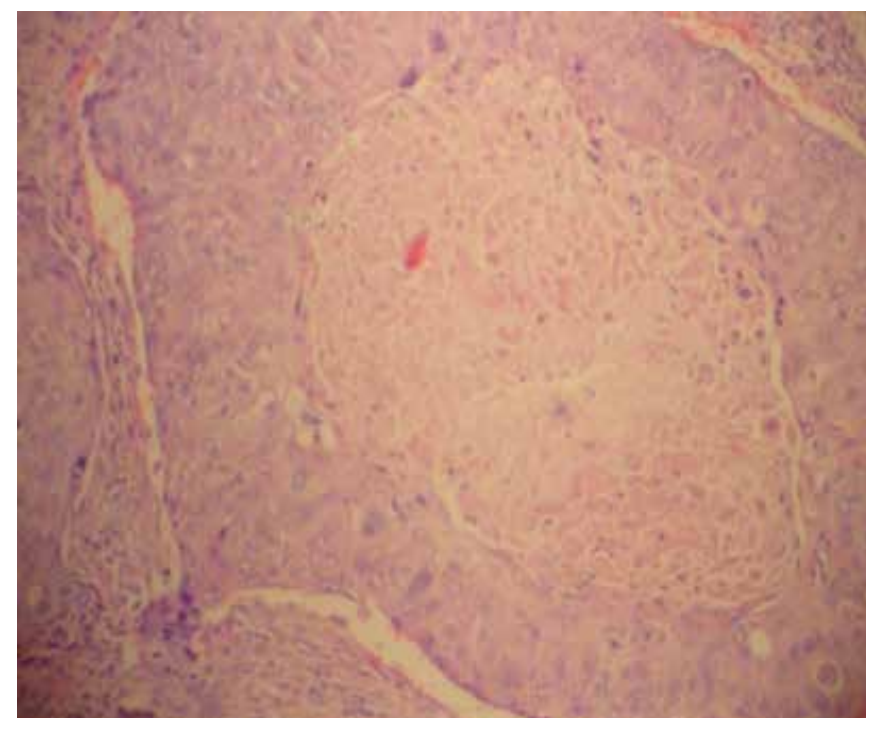

\section{DISCUSSION}

It is currently believed that ATs are derived from cells that have the ability to differentiate toward any of the appendages. In many lesions, the differentiation is uniform and the tumor can be recognized and categorized based on its resemblance to a normal appendage or part of it ${ }^{9,10,11 .}$

In this study 52 cases (98.11\%) were benign and only one $(1.8 \%)$ case was malignant. The commonest tumor was with follicular differentiation (96.22\%), all of them were benign and most of them were located in head and neck region. Similarly, in a study conducted by Yagoob et al total of 166 skin appendage tumors studied, 87.3\% were benign, while $12.6 \%$ were malignant. All tumors showed a predilection for occurrence on skin of head and neck (48.1\%), followed by upper limb (10.9\%) and lower limb (10.9\%). Out of total, $41.56 \%$ showed pilosebaceous differentiation, $37.34 \%$ showed eccrine differentiation, $14.45 \%$ showed apocrine differentiation and, $6.62 \%$ 
exhibited mixed differentiation ${ }^{12}$. Similarly in the study conducted by Samilo MO et al in total of 52 adnexal tumors seen, 46 were benign and six were malignant. Most of the lesions were distributed in head and neck region and were of follicular differentiation ${ }^{13}$.

\section{Pilomatricoma}

Although uncommon, PM, are quite common among all pilar tumors ${ }^{1}$. PM, also known as a calcifying epithelioma of Malherbe, is a benign skin tumor derived from the hair matrix $^{14}$. In 1961, Forbis and Helwig, after histochemical and electron microscopic analysis of 228 tumors, found the cell of origin to be the outer root sheath cell of the hair follicle ${ }^{15}$. They are single, skin-coloured or purplish lesions arise on the head and neck, but they may occur on any site ${ }^{1,6,8}$. This finding is consistent to our study, where the commonest site for PM was scalp.

Pilomatricoma (PM) was the most common benign tumor consisting of $72 / 244$ (30.1\%) cases, according to the study carried out by Song KY et $a l^{14}$.

Similarly in a study done by Yaqoob et al on tumours of pilo-sebaceous unit found that, PM was one of the five most common SAT encountered in their study ${ }^{12}$.

A female preponderance is noted in majority of the studies $^{14,15,16}$. In this study out of 18 cases, 13 cases occurred in females while five occurred in males.

In the study done by Zaman $\mathrm{S}$ et al maximum numbers of PM were observed in second and third decades ${ }^{17}$. In our study the maximum number of PM were diagnosed in second and fourth decade of life. In contrast, most of the studies concluded that one to 20 years was the most affected age group ${ }^{18,19}$.

The typical clinical picture of PM is the occurrence of a solitary, small, firm nodule, varying in size from five to 30 $\mathrm{mm}^{20}$.

\section{Keratoacanthoma}

KA is a common skin lesion, typically present as solitary, firm, skin colored reddish papules that rapidly progress to dome shaped sessile, nodule with central crateriform ulceration. The lesion has the same male and female predilection with a slightly more tendency to male individuals ${ }^{21}$.

Our study showed male predominance and most of the lesions were solitary.

Kerathoacanthoma was first described by Jonathon
Hutchison in 1889 as a distinct lesion with a crater-like facial ulcer ${ }^{22}$. This lesion; which most commonly involves the face and hands, is a rapidly-growing cutaneous tumor with atypical histopathological manifestations that resembles the squamous cell carcinoma (SCC). It leaves an atrophic scar when resolves ${ }^{23,24}$.

\section{Trichoepithelioma}

TE can be a single or multiple. This is a harmless benign tumor that arises on face after puberty ${ }^{25}$. The tumors are small $(<1 \mathrm{~cm})$, firm, rounded and shiny. They may be yellow, pink, brown or bluish. They usually gradually increase in number with age, occurring on both cheeks, eyelids and around the nose ${ }^{6}$.

In the study done by Saha A et al the second most common tumor seen was $\mathrm{TE}^{13}$. In our study also TE was found to be the third commonest tumor

In our study 7/12 cases of TE were distributed around nose. According to the various studies, TE remains primary differential diagnosis of ATs centered on nose $\mathrm{e}^{6,13,25}$.

Clinically as well as histologically, TE is considered in the differential diagnosis of basal cell carcinoma (BCC) $)^{25}$. This could be the fact that in this study also, most often, TEs were clinically diagnosed as BCC.

\section{Trichilemmoma}

Is a benign neoplasm that differentiates toward cells of the outer root sheath. The lesion is often seen in the face and neck region. Multifocal occurrence is associated with Cowden syndrome, patients with which exhibit hamartomatous intestinal polyposis as well as tricholemmoma ${ }^{26,27}$.

In our study TL was found most commonly to be located at back and in leg.

\section{Tumors with Sebaceous Differentiation}

SATs with sebaceous differentiation are uncommon, difficult to classify, and may be controversial. The main controversy concerns the microscopic features, which vary from well to poorly differentiated and sometimes undifferentiated varieties. When patients with numerous sebaceous adenomas and other neoplasms with sebaceous differentiation have an associated internal malignancy, the clinical condition is known as Muir-Torre syndrome ${ }^{7,8}$. However, in our study, tumors with sebaceous differentiation did not contribute to a significant proportion, so such association was not observed. 


\section{CONCLUSIONS}

1. Among pilar tumors, PM (33.9\%), KA (26.4\%) and TE (22.6\%) were the commonest tumors observed.

2. Pilomatricomas are commonly distributed in the head, neck and trunk and have female predominance and majority were present in fourth decade of life

3. Trichoepitheliomas are centered around nose, have male predominance and were present maximum in third decade of life

4. Keratoacanthomas are mostly seen in scalp, have female predominance and majority were found in fifth decade of life.

4. Malignant adnexal tumors were uncommon in our setting (1.8\%)

5. Tumors with sebaceous differentiation were almost found to be non contributory (3.7\%).

\section{Source of financial support}

None

\section{Acknowledgements}

We are very grateful to all our faculties, junior residents and technical staffs for their constant support. I extend my heartfelt thanks to all the participants of this study without whom this study would not have been completed.

\section{Conflict of Interest}

The authors declare no conflict of interest.

\section{REFERENCES}

1. Rudolph P. Benign adnexal skin tumors. Pathologue. 2002; 23: 71-8.

2. Rodriguez-Diaz E, Armio M. Mixed tumors with follicular differentiation: Complex neoplasms of the primary epithelial germ. Int J Dermatol. 1995; 34: 782-5.

3. Penneys NS. Immunohistochemistry of adnexal neoplasms. J Cutan Pathol. 1984; 11: 357-60.

4. Matsuda K, Doi T, Kosaka H, Tasaki N, Yoshioka H, Kakibuchi M. Sebaceous carcinoma arising in nevus sebaceus. J Dermatol. 2005; 32(8): 641-4.

5. Ansai S, Mihara I. Sebaceous carcinoma arising on actinic keratosis. Eur J Dermatol. 2000; 10(5): 385-8.

6. Storm CA, Seykora JT. Cutaneous adnexal neoplasms. Am J Clin Pathol. 2002; 118: 33-49.

7. Lever WF. Pathogenesis of benign tumors of cutaneous appendages and basal cell epithelioma. Arch Derm Syph. 1948: 57: 679.

8. Elder D, Elenitsas R, Ragsdale BD. Tumors of the epidermal appendages. In: Elder D, Elenitsas R, Jaworsky C, Johnson B Jr, editors. Lever's Histopathology of the Skin. 8 th ed. Philadelphia: Lippincott Williams and Wilkins; 1997. p. 747803.

9. Mehregan $\mathrm{AH}$. The origin of the adnexal tumors of the skin: A viewpoint. J Cutan Pathol. 1985; 12: 459-67.

10. Wong TY, Suster S, Cheek RF, Mihm MC Jr. Benign cutaneous adnexal tumors with combined folliculosebaceous, apocrine and eccrine differentiation: Clinicopathological and immunohistochemical study of eight cases. $\mathrm{Am} \mathrm{J}$ Dermatopathol. 1996; 18: 124-8.

11. Brownstein MH. The genodermatology of adnexal tumors. J Cutan Pathol. 1984; 11: 457-65.

12. Yaqoob N, Ahmad Z, Muzaffar S, Gill MS, Soomro IN and Hasan SH. Spectrum of cutaneous appendages tumours at Agha Khan University Hospital. J Pak Med Assoc. 2003; 53 (9): 427-31.

13. Samaila MO. Adnexal skin tumors in Zaria, Nigeria. Ann Afr Med. 2008 7: 6-10.

14. Song KY, Yoon DH, Ham EK, Lee YS. Clinico Pathological study on the skin appendageal tumors. Korean $J$ Pathol. 1989; 23(1): 111-121.

15. Forbis R and Helwig EB. Pilomatrixoma (Calcifying epithelioma). Arch Dermatol. 1961; 83: 606-617.

16. Alsaad KO, Obaidat NA and Ghazarian D. Skin adnexal neoplasm part 1: An approach to tumours of the pilosebaceous unit. J Clin Pathol. 2007; 60: 129-144.

17. Zaman S, Majeed S, Rehman F. Pilomatricoma- study on 27 cases and review of literature. Biomedica. 2009; 25: 69-72.

18. Duflo S, Nicollas R, Roman S, Magalon G, nad Triglia JM. Pilomatrixoma of the head and neck in children: A 
study of 38 cases and a review of the literature. Arch Otolaryngol Head Neck Surg. 1998; 124: 1239-1242.

19. Lan MY, Lan MC, Ho CY, Li WY and Lin CZ. Pilomatrixoma of the head and neck in children: A retrospective review of 179 cases. Arch Otolaryngol Head Neck Surg. 2003; 129: 1327-1330.

20. Julian CG, Bowers PW. A clinical review of 209 pilomatrixomas. J Am Acad Dermatol. 1998; 39: 191195.

21. Miot HA, Miot LD, da Costa AL, Matsuo CY, Stolf HO, Marques ME. Association between solitary keratoacanthoma and cigarette smoking: A casecontrol study. Dermatol Online J. 2006; 12: 2.

22. Ramos LM, Cardoso SV, Loyola AM, Rocha MA, Durighetto Júnior AF. Keratoacanthoma of the inferior lip: Review and report of case with spontaneous regression. J Appl Oral Sci. 2009; 17: 262-265.
23. Chauhan A, Chaudhary S, Agnihotri PG, Aadithya B. A solitary crateriform ulcer of the lower lip: a case report with review of literature. Indian J Dermatol. 2011; 56: 435-438. [PMC free article]

24. Hutchinson J. Morbid growths and tumours. 1. The "crateriform ulcer of the face," a form of acute epithelial cancer. Trans Pathol Soc London. 1889; 40: 275-281

25. Goldman P, Pinkus H, Rogin JR. Eccrine poroma: Tumors exhibiting features of the epidermal sweat duct unit. Arch Derm. 1956; 74: 511-21.

26. James, William D.; Berger, Timothy G et al. (2006). Andrews' Diseases of the Skin: Clinical Dermatology. Saunders Elsevier.

27. Rapini, Ronald P.; Bolognia, Jean L, Jorizzo, Joseph L. (2007). Dermatology: 2-Volume Set. St. Louis: Mosby. pp. 1699-1700. 